\title{
A Content Word Analysis in Elementary School 1-2 Graders' Korean Textbooks for Vocabulary Teaching of School Age Children with Language Impairment: Focused on Comparison before and after the 2009 Revision
}

\author{
Whasoo Kim¹, Jeongmin Cheon², Kyungyoon Choi², Seong Hee Choi \\ 'Department of Speech-Language Pathology, Daegu University, Gyeongsan, Korea \\ ${ }^{2}$ Major in Speech-Language Pathology, Department of Rehabilitation Science, Graduate School, Daegu University, Gyeongsan, Korea \\ ${ }^{3}$ Department of Audiology and Speech-Language Pathology, Catholic University of Daegu, Gyeongsan, Korea
}

\author{
학령기 언어장애 아동의 어휘교수를 위한 초등학교 1 2학년 국어 교과서 내용어 분석: \\ 2009 개정 전후 비교를 중심으로 \\ 김화수 ${ }^{1} \cdot$ 천정민 $^{2} \cdot$ 최경윤 ${ }^{2} \cdot$ 최성희 ${ }^{3}$ \\ 대구대학교 언어치료학과', 대구대학교 일반대학원 재활과학과 언어치료전공', 대구가톨릭대학교 언어청각치료학과 ${ }^{3}$
}

\begin{abstract}
Purpose: The purpose of this study is the goal that school age children with language impaired who have some limit to language in their elementary school age let use words from revised Korean language Textbooks which are educated by teachers or peers at real school and let them continue to generalization. Methods: The classified vocabulary from elementary school 1-2 graders' Korean textbook (2009 revision curriculum) into nouns, verbs, and adjectives and compared with the study of before 2009 revision which analyzed vocabulary from Korean textbook (7th curriculum). Results: This study indicated that nouns in 2009 revision included more noun (human) and noun (animal). Noun (natural) and noun (other), however, were less frequent. Both curriculums included more action verb than state verb. Also, both curriculums included more icon adjective, but in 2009 revision the frequency of icon adjective was decreased while the frequency of emotive adjective and demonstrative adjective was increased. Conclusion: The result of this study offers base line data for educating from school age children with language impairment.
\end{abstract}

Key Words: School age children with language impairment, Vocabulary, Elementary school, Korean textbooks, 2009 revision.

Received: June 11, 2016 / Revised: June 27, 2016 / Accepted: July 13, 2016

Correspondence: Whasoo Kim, Department of Speech-Language Pathology, Daegu University, 201 Daegudae-ro, Jillyang-eup, Gyeongsan 38453, Korea Tel: +82-53-850-4324 / Fax: +82-53-850-4329 / E-mail: whasoolang@daum.net

\section{INTRODUCTION}

아동들의 어휘 발달은 음운 체계에 대한 지식의 증가, 단어 학습에 대한 내적 제약의 작동, 전반적인 인지 능력의 발달 등 과 같은 아동의 내부 변화를 통하여 이루어진다(Hoff, 2001). 또한 아동들의 어휘 발달은 이러한 아동의 내부 변화뿐만 아니
라 일상생활의 대화에서 노출되는 말의 양에 크게 좌우되기도 한다(Huttenlocher et al., 1991). 때문에 일상생활에 노출되어 있는 어휘, 즉 학령기 아동의 학교 현장에서의 어휘 학습은 아 동의 어휘 발달에 매우 중요하다고 할 수 있다.

어휘는 음성 언어 및 문자 언어를 이해하는 데 매우 중요한 역 할을 하며 원활한 의사소통을 하기 위한 핵심적인 요소이다. 특 
히 학령기에 들어서게 되면, 아동들은 동화, 생활문, 설명문, 동 시 등과 같은 다양한 글의 종류를 통해서 더 많은 어휘를 접하 게 되고, 이러한 어휘를 중심으로 문장 및 문단의 형태로 확장 시켜 글을 이해하고 표현하게 된다.

언어학습장애 아동들은 단단어나 짧은 문장을 통해 제한된 의사소통을 하며, 여기서 사용되는 단어의 다양성 또한 또래에 비해 떨어져 적은 어휘량을 보인다고 보고되었다(Catts et al., 1999; Kuder, 1997). 따라서 언어장애를 가진 아동을 대상으로 교육을 제공할 때는 그들의 수준에 적합한 어휘를 선택하여 의 사소통하도록 유도할 필요가 있으며, 이때 신뢰도 높은 어휘를 선정하는 것이 매우 중요하다고 할 수 있다.

교과서는 교육과정의 기본 목표를 구현할 목적으로 선정되며 학생의 발달 수준을 감안하여 내용을 재조직한 학습의 기본 교재이다. 우리나라의 교육현장에서 교과서는 가장 중심이 되 는 교재 및 학습 자료로 사용될 뿐만 아니라 교과서의 그 내용 과 순서에 따라 교수 학습 활동이 전개되며, 학습 평가의 기준이 되기도 한다(Kim, 2009). 또한 학령기 아동들은 학교에서의 읽 기를 통해 많은 어휘를 학습하기 때문에(Catts \& Kamhi, 2005), 교과서에 나타난 어휘는 다른 어휘에 비해 동일 언어연령을 가 진 학령기 언어장애 아동을 교육할 때 사용할 수 있는 가장 신 뢰도가 높은 어휘라고 할 수 있다.

또한 인간의 모든 활동은 언어와 구별되어 나타날 수 없다. 학령전기 아동은 가정에서 말하고 듣고 쓰는 등의 활동을 계 속하여 언어를 경험하지만 학령기에 들어서게 되면 아동에게 가장 많은 언어활동이 일어나는 곳은 가정에서 학교로 변화하 게 된다. 즉 학령기 아동들은 학교에서 또래와의 의사소통 및 학교 교육을 통해 다양한 언어활동을 경험하고 새로운 사고를 갖게 되는 것이다. 때문에 학교 교육은 아동의 지식과 사고의 폭을 확장시키는 중요한 역할을 하며, 그 중심에는 학교 교과서 가 자리 잡고 있기 때문에 학교 교과서에 나타난 어휘를 학습 하는 것은 매우 중요하다고 할 수 있다.

초등학교 교과서는 2007년 교육과정 개정 이후 2009년에 교 육과정 총론이 만들어졌으며, 2011년에 국어과 교육과정이 고 시된 후 공식적으로 2009 국어과 교육과정으로 개정되었다 (Lee, 2013).

본 연구에서는 2009 개정 이전과 개정 이후의 국어 교과서 어휘를 비교하여 새로 사용된 어휘와 빈도수가 높은 어휘를 알 아보고자 하였다. 이를 위해 먼저 초등학교 1 2학년 국어 교과 서의 본문에 나오는 어휘 가운데 비교적 많은 빈도수를 차지하 는 명사와 더불어, 동사, 형용사를 추출하였다.

Choi(2001)는 아동의 어휘이해 발달 수준에 적합한 주요 내 용어 선정 연구에서 '명사, 동사, 형용사를 의사소통에서 의미 전달의 핵심적인 역할을 하는 내용어로 분류하고 있다. 기능어
는 수적으로 한정되어 있으며 변화하지 않는 속성을 지니지만 내용어는 언어의 역사적 발달 과정에서 의미나 형식면에서 계 속 변화하는 속성을 지니며, 언어의 기본어휘 혹은 주요 어휘 를 선정하는 데 있어서 중심이 된다. 따라서 의사소통의 핵심적 인 역할을 하는 명사, 동사, 형용사의 습득은 단어 수준을 넘어 서 어휘를 문장, 구, 절로 확장시켜 학령기 언어장애 아동의 의 사소통에까지 영향을 줄 수 있다. 이에 따라 본 연구에서는 명 사, 동사, 형용사의 어휘들을 빈도수로 분석하였으며, 이를 2009 개정 이전과 이후 어휘로 나누어 비교하였다.

이러한 연구결과를 통해 학령기 언어장애 아동의 어휘 이해 발달 수준에 적합한 내용어를 선정하여 바람직한 어휘 발달 지 도에 활용함과 동시에 교육적 임상에 기여하고자 하며, 효율적 인 교육의 기초자료로 사용되길 기대한다.

\section{MATERIALS AND METHODS}

\section{연구 도구}

본 연구에서는 2009년 개정된 초등학교 1 2학년 교과서인 국어 1-1(가), 국어 1-1(나), 국어 1-2(가), 국어 1-2(나), 국어 2-1(가), 국어 2-1(나), 국어 2-2(가), 국어 2-2(나) 중에서 본문 에 나오는 명사, 동사, 형용사 어휘를 분석하였다. 그리고 2009 교육과정 이전인 제7차 교육과정의 1 2학년 국어 교과서 어휘 를 분석한 Hyun(2003) 연구의 부록을 참고하여 명사, 동사, 형 용사 어휘를 찾아 그 빈도수를 1 위에서 30 위까지로 나열하고, 비교분석하였다.

\section{연구 절차}

초등학교 1 2학년의 국어 교과서의 본문에 나오는 모든 단 어를 분류하여 텍스트 파일로 정리하였다. 또한 신뢰도를 높이 기 위하여 '말뭉치 프로그램'을 사용하여 재분석하였다. 어휘별 로 분류된 자료를 명사, 동사, 형용사로 나누어 분석하였다. 어 휘별로 품사를 정할 때의 기준은 다음과 같다. 명사는 사물의 이름을 나타내는 단어로 단어가 단독으로 명사로 쓰인 경우, 같 은 의미를 갖는 명사 단어에 조사가 붙어 명사형이 된 단어, 조 사가 붙어 줄여진 단어는 한 단어로 빈도를 계산하였다(예. 나, 난, 내게). 또한 같은 의미를 가진 단어로 존칭을 나타내는 단어 또한 한 단어로 빈도를 계산하였다(예. 엄마와 어머니). 동사는 사물의 움직임을 나타내는 단어로 어간과 어미로 나누고 어간 의 기본형으로 통일하여 빈도를 계산하였다. 마지막으로 형용 사는 사물의 성질이나 상태를 나타내는 단어로 그 기준을 정하 였다.

모든 어휘의 분류는 교과서 본문에서 중심이 되는 어휘를 기 준으로 하였다. 따라서 명사는 사람관계명사와 동물관계명사, 
대자연관계명사로 분류하였고, 동사는 동작동사와 상태동사로 분류하였으며, 형용사는 성상형용사와 감정형용사, 지시형용사, 보조형용사, 수량형용사로 분류하여 분석하였다.

\section{자료 및 결과 처리}

교과서 어휘를 명사, 동사, 형용사로 분류하여, 빈도 분석을 실시하고, 그 결과에 따라 빈도가 가장 높은 어휘부터 30위까 지의 어휘를 기술하였다. 그리고 Hyun(2003) 연구의 부록에 나타난 명사, 동사, 형용사 각각의 빈도와 비교 분석하였다.

\section{RESULTS}

\section{명 사}

제7차 교육과정과 2009 개정 교육과정에 나타난 초등학교 1 2학년 국어 교과서의 명사 어휘를 빈도순으로 나열한 것은 Appendix 1과 같으며 이러한 명사 어휘의 의미기준별 비교는 Figure 1과 같다.

제7차 교육과정의 1 2학년 국어 교과서를 분석한 결과, 빈도 수가 높은 1 30위까지의 어휘 중에서 기타 어휘(것/수/때/집/소 리/날/생각/속/모습/일/책/이름/일기/나라/학교)가 50\%로 가장 높았고, 사람관계어휘(친구/사람/선생님/아버지/할머니/아이)와 대자연관계어휘(나무/비/하늘/꽃/달/풀)가 $20 \%$ 로 동일하게 나 타났으며, 동물관계어휘(말/강아지/토끼)는 $10 \%$ 로 가장 적게 나타났다.

2009 개정 교육과정의 1 2학년 국어 교과서를 분석한 결과, 빈도수가 높은 1 30위까지의 어휘 중에서 제7차 교육과정의 국

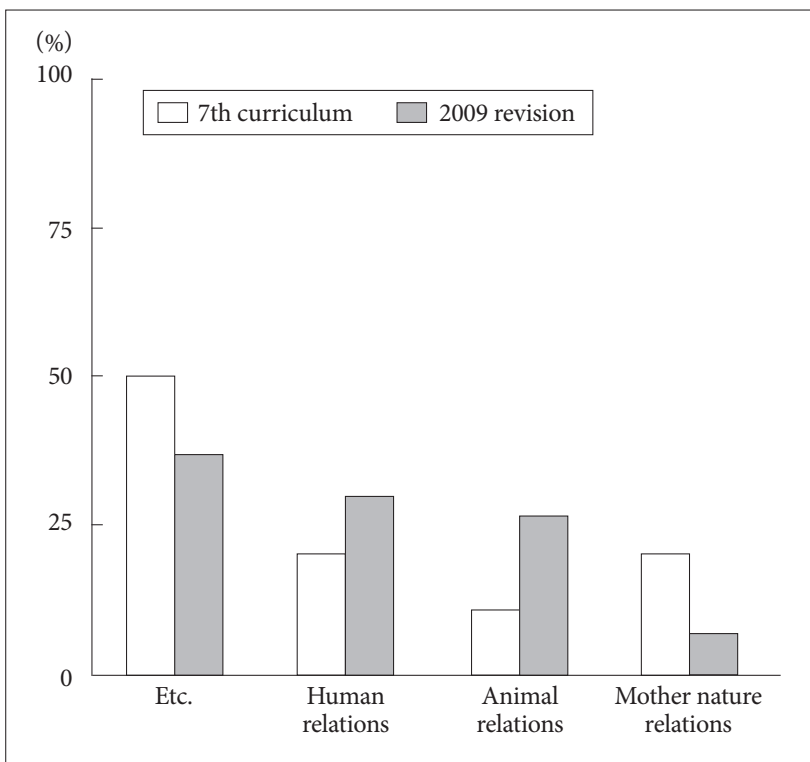

Figure 1. The comparison of the categories in semantic classification of noun between $7^{\text {th }}$ curriculum and 2009 revision.
어 교과서와 동일하게 기타 어휘(소리/집/날/때/모두/얼굴/정말/ 마음/멋쟁이/속/일)가 $36.7 \%$ 로 가장 많게 나타났으나 그 비율 은 더 낮았다. 사람관계어휘(친구/엄마/동생/사람/선생님/아저 씨/어머니/할머니/아기)는 $30 \%$ 로 제7차 교육과정보다 $10 \%$ 가 량 더 높게 나타났고, 동물관계어휘(말/돼지/개미/암탉/강아지/ 호랑이/소/오소리)는 $26.7 \%$ 로 제7차 교육과정보다 $6.7 \%$ 가량 더 높게 나타났다. 마지막으로 대자연관계어휘(물/바람)는 $6.9 \%$ 로 가장 적게 나타났는데 이는 제7차 교육과정에 나타난 대자연관 계어휘에 비해 $13.1 \%$ 적어진 비율이다.

이를 통해 2009 개정 교육과정에서는 사람관계어휘와 동물 관계어휘의 비중이 더 높아진 것을 알 수 있으며, 그에 비해 대 자연관계어휘의 비중이 눈에 띄게 낮아진 것을 알 수 있다. 특 히 사람관계어휘와 동물관계어휘는 2009 개정된 교과서에 '엄 마, 동생, 아저씨, 돼지, 개미, 암탉, 호랑이, 소, 오소리' 등의 새 로운 어휘가 추가된 것으로 나타났다.

\section{동 사}

제7차 교육과정과 2009 개정 교육과정에 나타난 초등학교 1 2학년 국어 교과서의 동사 어휘를 빈도순으로 나열한 것은 Appendix 2와 같으며 이러한 동사 어휘의 의미기준별 비교는 Figure 2와 같다.

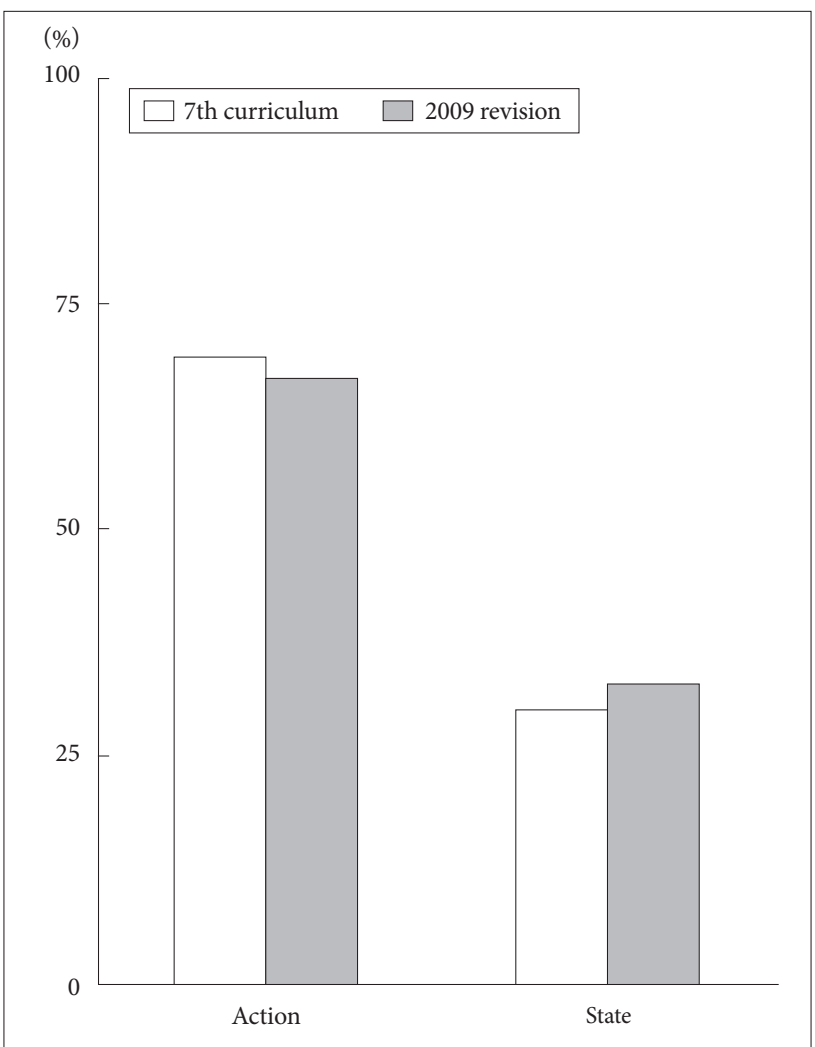

Figure 2. The comparison of the categories in semantic classification of verb between $7^{\text {th }}$ curriculum and 2009 revision. 
제7차 교육과정의 1 2학년 국어 교과서를 분석한 결과, 빈도 수가 높은 1 30위까지의 어휘 중에서 동작동사(하다/보다/주 다/가다/말하다/오다/않다/나다/먹다/쓰다/부르다/만들다/들 다/읽다/내다/타다/잡다/말다/나오다/나가다/놓다)는 $70 \%$ 로 나타났고, 상태동사(있다/되다/살다/알다/웃다/듣다/생각하다/ 좋아하다/생기다)는 $30 \%$ 로 나타났다.

2009 개정 교육과정의 1 2학년 국어 교과서를 분석한 결과 에서는 빈도수가 높은 1 30위까지의 어휘 중 동작동사(하다/보 다/가다/주다/오다/먹다/말하다/나다/않다/나오다/놀다/만들 다/나가다/들다/말다/그러다/다가가다/놀리다/뛰다/입다)가 $66.7 \%$ 로 상태동사(있다/되다/지다/알다/웃다/살다/듣다/보이 다/생각하다/울다)보다는 높게 나타났다. 그러나 이러한 동작동 사는 제 7 차 교육과정에 비해 개정된 교육과정에서 $6.7 \%$ 가량 사용 빈도가 낮아진 반면 상태동사는 $33.3 \%$ 로 개정 후가 $6.7 \%$ 가량 높아진 것으로 나타났다.

한편 '지다, 놀다, 그러다, 보이다, 다가가다, 울다, 놀라다, 뛰다, 입다'는 2009 개정 국어 교과서에 새롭게 실린 동사어휘이다.

\section{형용사}

제7차 교육과정과 2009 개정 교육과정에 나타난 초등학교 $1 \sim 2$ 학년 국어 교과서의 형용사 어휘를 빈도순으로 나열한 것은 Appendix 3과 같으며, 이러한 형용사 어휘의 의미기준별 비교 는 Figure 3 과 같다.

제7차 교육과정의 1 2학년 국어 교과서를 분석한 결과, 빈도 수가 높은 1 30위까지의 어휘 중에서 성상형용사(좋다/있다/없

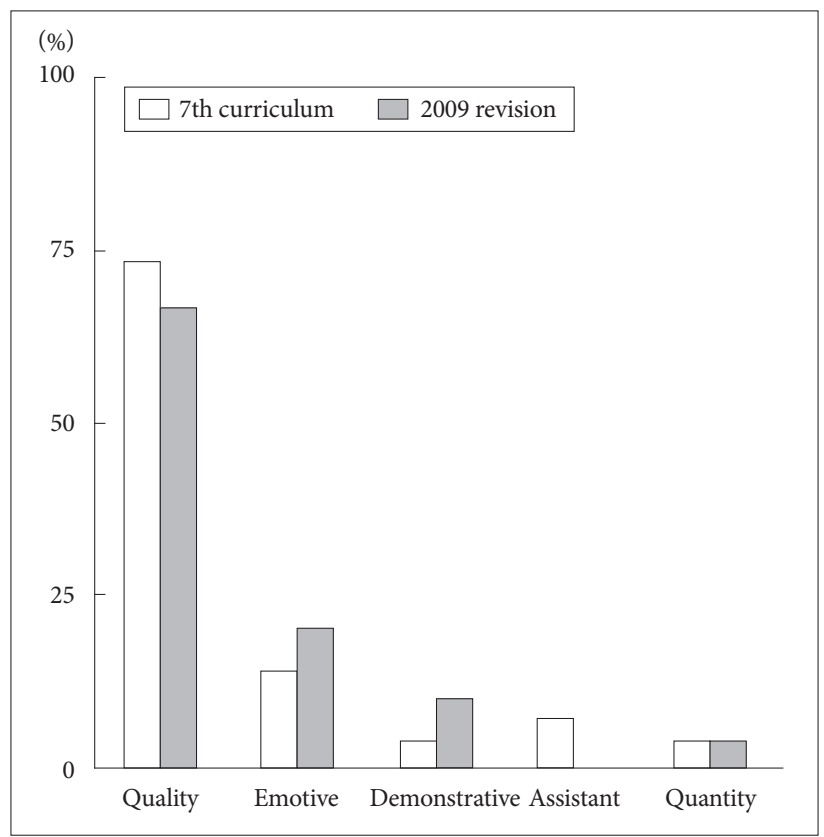

Figure 3. The comparison of categories in semantic classification of adjective between $7^{\text {th }}$ curriculum and 2009 revision.
다/크다/아프다/모르다/같다/아름답다/아니다/쉽다/밝다/예쁘 다/맛있다/중요하다/시끄럽다/작다/커다랗다/길다/덥다/춥다/ 나쁘다/귀엽다)가 $73.3 \%$ 로 가장 많았다. 다음으로 감정형용사 (재미있다/고맙다/기쁘다/즐겁다)는 $3.4 \%$, 보조형용사(싶다/못 하다)는 $6.7 \%$ 로 나타났으며, 지시형용사(그렇다)와 수량형용사 (많다)는 3.3\%로 동일하게 나타났다.

2009 개정 교육과정의 1 2학년 국어 교과서를 분석한 결과 에서는 빈도수가 높은 1 30위까지의 어휘 중에서 제7차 교육 과정의 국어 교과서와 동일하게 성상형용사(없다/작다/좋다/크 다/맛있다/아프다/같다/예쁘다/괜찮다/길다/따뜻하다/커다랗 다/곱다/귀엽다/신기하다/아니다/빨강다/착하다/이상하다/힘들 다)가 $66.7 \%$ 로 가장 많은 것으로 나타났으나 그 비율은 더 낮 았다. 감정형용사(고맙다/곤란하다/무섭다/재미있다/미안하다/ 즐겁다)는 $20 \%$ 로 제 7 차 교육과정보다 $6.6 \%$ 더 높게 나타났고, 지시형용사(이러하다/그러하다/어떠하다)는 $10 \%$ 로 제7차 교육 과정보다 $6.7 \%$ 가량 더 높게 나타났다. 마지막으로 수량형용사 (많다)는 $3.3 \%$ 로 제 7 차 교육과정과 동일하게 나타났다.

형용사의 경우 제 7 차 교육과정과 2009년 개정된 교육과정의 국어 교과서에서 모두 성상형용사의 비율이 높은 것은 초등학 교 저학년 아동에게 성상형용사의 쓰임이 더 많기 때문인 것으 로 보이며, 감정형용사의 중요성은 2009 개정된 국어 교과서에 서 더 강조되어 빈도수가 높아진 것으로 보인다. 한편 '이러하 다, 괜찮다, 곤란하다, 따뜻하다, 미안하다, 곱다, 신기하다, 어떠 하다, 빨강다, 착하다, 이상하다는 2009 개정 국어 교과서에 새 롭게 실린 형용사 어휘이다.

\section{DISCUSSIONS}

이 연구는 2009년 개정된 초등학교 1 2학년 국어 교과서의 어휘를 그 이전 교과과정인 제7차 교육과정 국어 교과서의 어휘 와 비교하여 분석하였다.

제7차 교육과정에 나타난 초등학교 1 2학년 국어 교과서 어 휘 중 가장 중심이 되는 명사를 포함한 동사, 형용사 어휘를 빈 도수가 높은 1 위부터 30 위까지로 분류하고, 이를 2009 개정된 교육과정과 비교한 결과는 다음과 같다.

명사는 두 교육과정 모두 기타어휘가 각각 $50 \%$ 와 $36.7 \%$ 로 가장 많았고 그 이외에 제7차 교육과정 국어 교과서의 경우 사 람관계어휘와 대자연관계어휘, 동물관계어휘 순으로 나타났으 며, 2009 개정된 교육과정 국어 교과서는 사람관계어휘, 동물 관계어휘, 대자연관계어휘 순으로 나타났다. 즉 2009 개정된 교 육과정에서는 사람관계어휘와 동물관계어휘의 빈도가 높아져 그 중요성이 강조된 것으로 보인다.

동사는 두 교육과정 모두 동작동사가 각각 $70 \%$ 와 $63.3 \%$ 로 
상태동사 보다 더 높게 나타났으나 그 비율은 제7차 교육과정 국어 교과서에서 더 높았고, 상태동사는 2009 개정 교육과정에 서 빈도수가 더 높은 것으로 나타났다.

형용사는 두 교육과정 모두 성상형용사가 각각 $73.3 \%$ 와 $66.7 \%$ 로 빈도수가 가장 높게 나타났고, 그 이외에 제7차 교육 과정 국어 교과서의 경우 감정형용사, 보조형용사, 수량형용사 순으로, 2009 개정된 교육과정 국어 교과서는 감정형용사, 지 시형용사, 수량형용사 순으로 나타났다.

본 연구는 초등학교 1 2학년 국어 교과서에 나타난 어휘 중 명사, 동사, 형용사를 추출하여 빈도를 분석하고 2009 개정 이 전과 이후의 어휘를 비교함으로써 최신 교과서에서 사용된 어 휘의 동향을 파악할 수 있다. 이와 더불어 언어치료 임상현장 에서 학령기 언어장애 아동의 초기 문식성 중재를 위한 기초자 료로써 가치가 있으리라 기대한다. 이러한 의의에도 불구하고 본 연구에는 제한점이 있으며, 이는 추후 연구를 위한 발화점 이 될 수 있을 것이다.

먼저, 본 연구에서 분석한 어휘를 포함하여 다른 품사의 어 휘 역시 접근할 필요가 있으며, 의미범주별 분류는 더욱 다양 한 의미기준에 근거하여 분석하기를 제안한다. 또한 초등학교 1 2학년 이외에도 다른 학년의 교과서와 다른 과목의 교과서 가 분석되어질 필요가 있다. 학령기의 경우 임상현장에서 한 회 기에 여러 개의 새 어휘를 익히곤 하기 때문에 한 품사당 30 개 의 어휘 수로는 부족할 수 있다. 이러한 점을 보완하기 위해서 다른 품사의 어휘를 더 활용하거나 교과서 어휘 이외의 어휘를 함께 사용하는 것이 좋을 것이라 사료된다. 학령기 언어장애에
대한 관심이 증대하고 있는 현재 연구 상황에서 아동이 단어학 습을 위해 어휘의 다양성 및 빈도수 범주의 증대 등을 통해 연 구가 확대되기를 기대한다.

중심 단어 : 학령기 언어장애 아동·어휘·초등학교. 국어 교과서· 2009 개정.

\section{REFERENCES}

Catts, H. W., Fey, M. E., Zhang, X., \& Tomblin, J. B. (1999). Language basis of reading and reading disabilities: evidence from a longitudinal investigation. Scientific Studies of Reading, 3(4), 331-361.

Catts, H. W. \& Kamhi, A. G. (2005). Causes of reading disabilities. In Catts, H. W. \& Kamhi, A. G. Language and reading disabilities (2nd ed.). Boston: Allyn and Bacon.

Choi, G. H. (2001). A study on the selection of the Essential Content Words, according to level of the Children's Vocabulary understanding: Focused on Elementary School 6th Grader 'Noun, Verb, Adjective' (unpublished master's thesis). Daegu National University of Education, Daegu.

Kim, H. J. (2009). The Contents and methods of an history education. Seoul: With a Book.

Hoff, E. (2001). Language development (2nd ed.). Stamford, CT: Wadsworth/ Thomson Learning.

Huttenlocher, J., Haight, W., Bryk, A., Seltzer, M., \& Lyons, T. (1991). Early vocabulary growth: relation to language input and gender. Developmental Psychology, 27(2), 236-248.

Hyun, M. J. (2003). A Study on Vocabulary Used in Elementary-School Korean Textbook: Focused on Korean textbooks of the lower grades (unpublished master's thesis). Pai Chai University, Daejeon.

Kuder, S. (1997). Teaching students with language and communication disabilities. Boston, MA: Allyn \& Bacon.

Lee, J. S. (2013). The issue and future task of new Korean language textbook development in elementary school. Journal of Korea Elementary Language Education, 53, 207-231. 


\section{APPENDIX}

Appendix 1. The comparison of noun frequency in 7th curriculum and 2009 revision

\begin{tabular}{|c|c|c|c|c|c|c|c|c|c|c|c|}
\hline \multicolumn{6}{|c|}{ 7th curriculum } & \multicolumn{6}{|c|}{2009 revision } \\
\hline Word & Frequency & Word & Frequency & Word & Frequency & Word & Frequency & Word & Frequency & Word & Frequency \\
\hline 것 & 120 & 아버지 & 37 & 책 & 27 & 친구 & 61 & 사람 & 32 & 어머니 & 24 \\
\hline 수 & 89 & 나무 & 36 & 이름 & 26 & 엄마 & 57 & 암탉 & 32 & 호랑이 & 24 \\
\hline 때 & 73 & 강아지 & 36 & 할머니 & 25 & 소리 & 53 & 강아지 & 30 & 마음 & 23 \\
\hline 친구 & 65 & 토끼 & 35 & 일기 & 25 & 집 & 41 & 물 & 30 & 소 & 23 \\
\hline 집 & 62 & 생각 & 34 & 아이 & 25 & 말 & 39 & 모두 & 27 & 할머니 & 23 \\
\hline 사람 & 59 & 비 & 34 & 나라 & 25 & 돼지 & 35 & 선생님 & 27 & 아기 & 22 \\
\hline 말 & 54 & 속 & 32 & 꽃 & 25 & 동생 & 34 & 바람 & 26 & 멋쟁이 & 21 \\
\hline 소리 & 47 & 모습 & 32 & 학교 & 24 & 개미 & 33 & 아저씨 & 25 & 속 & 21 \\
\hline 날 & 46 & 일 & 31 & 달 & 24 & 날 & 33 & 얼굴 & 25 & 일 & 21 \\
\hline 선생님 & 39 & 하늘 & 27 & 풀 & 23 & 때 & 32 & 정말 & 25 & 오소리 & 20 \\
\hline
\end{tabular}

Appendix 2. The comparison of verb frequency in 7 th curriculum and 2009 revision

\begin{tabular}{|c|c|c|c|c|c|c|c|c|c|c|c|}
\hline \multicolumn{6}{|c|}{ 7th curriculum } & \multicolumn{6}{|c|}{2009 revision } \\
\hline Word & Frequency & Word & Frequency & Word & Frequency & Word & Frequency & Word & Frequency & Word & Frequency \\
\hline 하다 & 267 & 먹다 & 48 & 생각하다 & 30 & 하다 & 214 & 나다 & 38 & 듣다 & 20 \\
\hline 있다 & 181 & 쓰다 & 45 & 내다 & 30 & 있다 & 158 & 않다 & 37 & 말다 & 20 \\
\hline 보다 & 162 & 부르다 & 44 & 타다 & 29 & 보다 & 89 & 나오다 & 30 & 그러다 & 19 \\
\hline 되다 & 139 & 살다 & 43 & 잡다 & 29 & 가다 & 79 & 알다 & 25 & 보이다 & 16 \\
\hline 주다 & 107 & 만들다 & 42 & 좋아하다 & 27 & 주다 & 78 & 놀다 & 23 & 다가가다 & 15 \\
\hline 가다 & 93 & 들다 & 36 & 말다 & 27 & 되다 & 74 & 만들다 & 23 & 생각하다 & 15 \\
\hline 말하다 & 89 & 웃다 & 34 & 나오다 & 26 & 오다 & 60 & 웃다 & 23 & 울다 & 15 \\
\hline 오다 & 76 & 알다 & 34 & 생기다 & 25 & 먹다 & 53 & 나가다 & 22 & 놀라다 & 14 \\
\hline 않다 & 62 & 듣다 & 34 & 나가다 & 25 & 말하다 & 40 & 들다 & 21 & 뛰다 & 14 \\
\hline 나다 & 55 & 읽다 & 31 & 놓다 & 25 & 지다 & 40 & 살다 & 21 & 입다 & 14 \\
\hline
\end{tabular}

Appendix 3. The comparison of adjective frequency in 7th curriculum and 2009 revision

\begin{tabular}{|c|c|c|c|c|c|c|c|c|c|c|c|}
\hline \multicolumn{6}{|c|}{7 th curriculum } & \multicolumn{6}{|c|}{2009 revision } \\
\hline Word & Frequency & Word & Frequency & Word & Frequency & Word & Frequency & Word & Frequency & Word & Frequency \\
\hline 좋다 & 76 & 고맙다 & 18 & 맛있다 & 9 & 없다 & 51 & 이러하다 & 17 & 곱다 & 9 \\
\hline 있다 & 68 & 아름답다 & 16 & 중요하다 & 9 & 작다 & 42 & 괜찮다 & 15 & 귀엽다 & 9 \\
\hline 없다 & 67 & 못하다 & 15 & 시끄럽다 & 8 & 좋다 & 38 & 곤란하다 & 12 & 신기하다 & 9 \\
\hline 많다 & 44 & 아니다 & 15 & 작다 & 8 & 크다 & 26 & 길다 & 12 & 아니다 & 9 \\
\hline 싶다 & 29 & 쉽다 & 13 & 커다랗다 & 8 & 맛있다 & 22 & 무섭다 & 12 & 어떠하다 & 9 \\
\hline 크다 & 28 & 밝다 & 11 & 길다 & 8 & 아프다 & 20 & 재미있다 & 11 & 빨강다 & 8 \\
\hline 재미있다 & 24 & 그렇다 & 11 & 덥다 & 7 & 같다 & 19 & 그러하다 & 10 & 착하다 & 8 \\
\hline 아프다 & 24 & 기쁘다 & 11 & 춥다 & 7 & 고맙다 & 18 & 따뜻하다 & 10 & 이상하다 & 7 \\
\hline 모르다 & 22 & 예쁘다 & 11 & 나쁘다 & 7 & 많다 & 17 & 미안하다 & 10 & 즐겁다 & 7 \\
\hline 같다 & 19 & 즐겁다 & 10 & 귀엽다 & 7 & 예쁘다 & 17 & 커다랗다 & 10 & 힘들다 & 7 \\
\hline
\end{tabular}

